\title{
Use of Primary Care Emergency Services in Norway: Impact of Birth Country and Duration of Residence
}

\author{
URSULA S. GOTH ${ }^{1,2, *}$ AND GEIR GODAGER ${ }^{3,4}$ \\ ${ }^{1}$ Oslo and Akershus University College, Faculty for Health Sciences \\ ${ }^{2}$ Oslo University Hospital, Southern and Eastern Norway Regional Health Authority, \\ Norwegian Centre for Minority Health Research \\ ${ }^{3}$ University of Oslo, Faculty of Medicine, Institute of Health and Society, \\ Department of Health Management and Health Economics \\ ${ }^{4}$ Akershus University Hospital, Southern and Eastern Norway Regional Health Authority, \\ Health Services Research Centre
}

\begin{abstract}
:
Objective: In Norway, the General Practitioner Scheme was established in 2001. Satisfaction with the system is generally high. However, people often choose to visit community-based emergency wards (EW) for routine care instead. The aim of this paper is to describe which factors influence the choice of seeking care at the EW.

Design, setting, and patients: Prior national research on utilization patterns has been based mostly on surveys showing a low response rate. By using merged register data, we analyzed the choice of the EW as a care provider in Oslo (Norway) for 2006 and 2007. Applying 1,934,248 observations of 279,531 different individuals, we estimated the probability of choosing the emergency ward for the Norwegian-born population as well as for the14-largest immigrant groups. Substantial variation between groups was identified.

Main outcome: The proportion of EW visits was highest among patients from Somalia (11.7 percent) while the lowest proportion of EW users was among immigrants from Germany and Vietnam (5.3 percent). The results vary substantially within individual migrant groups; gender, age, and the duration of residence each influence the probability of visiting an EW.

Conclusions: We found large differences in the probability of using an EW between individuals from immigrant populations, presumably because of barriers in access to primary care. Continuity in the physician-patient relationship is an important policy goal. A suggestion for policy is thus to improve communication about the organization of the Norwegian health-care sector to newly arrived immigrants, as well as to patients at the EW.
\end{abstract}

Keywords: Migrant/immigrant, Norway, utilization, access, general practitioner

Grant: This project has been financially supported by the Norwegian Extra Foundation for Health and Rehabilitation through EXTRA funds.

Conflict of interest: The authors have no actual or potential conflict of interest including financial, personal or other relationships with other organizations that could inappropriately influence or be perceived to influence our work. 


\section{Introduction}

Over the last decade, public health policy in Norway has undergone structural changes with the aim of reducing inequities in service provision (Helse- og omsorgsdepartementet, 2003).

Norway's primary healthcare system includes health promotion and prevention, health clinics, emergency care, and immigrant health care. All long term residents are insured in the Norwegian Social Insurance Scheme and are beneficiaries of primary health care.

Primary Care out-of hour service is obtainable at the emergency ward (EW). Internationally the EW or emergency departments are anchored as hospital based services. In Norway the EW is part of the primary health care services.

In Oslo, the recruitment area for this study, the EW is organized as a safety net for the population and has a coordinating function for urgent treatment and emergency assistance except for the pre-hospital services, open 24 hours daily.

In 2001 a key reform was introduced, the Regular General Practitioner Scheme (GP Scheme), under which patients voluntarily choose a general practitioner (GP). The GP serves as a gatekeeper for secondary care and is responsible for preventive care and follow-up treatment and is, or should be, the first point of contact within the primary health-care system, financed by national taxation. The vast majority of inhabitants participate in this RGP Scheme organized as a patient list system (Krasnik \& Paulsen, 2009, Helsedirektoratet, 2011). Statistics Norway notes that, as of 2011, 12 percent of Norway's population were immigrants or descendants of immigrants. In Oslo, the capital, the immigrant population comprised 28 percent of the population (Statistics Norway, 2011).

The GP Scheme in Norway is available to all legal residents intending to stay longer than six months. Individuals coming to a foreign culture with an unfamiliar language may encounter linguistic and cultural barriers that could, in turn, cause a different utilization pattern with respect to primary care services. The result may be poorer quality of care (Westin \& Krokstad, 2003).

Our point of departure is that newly arrived residents are not equally well-informed about the organizational structure of the health sector. Norway is a country where people have, on average, a high socio-economic status. Migrants from non-Western societies often have a lower socio-economic status and encounter problems in obtaining access to health-care services (Huijts \& Eikemo, 2009). A stable, ongoing relationship with a GP may contribute to a broader perspective on a patient's situation and facilitate appropriate treatment and preventive care. The diversity of the immigrant population along the dimensions revealed in this study both indicates the challenge and helps suggest the path forward toward the goal of providing equal access to health care. Residents seeking medical care for acute illness may choose between two providers within the primary health-care system, an assigned GP or the local EW.

Local research including immigrants was, up to this date, based mostly on questionnaire surveys showing a low response rate.

Equity in health care is the absence of systematic disparities in health. With the growing diversity focus must be set on accessibility to health care services and objective data is needed to outline actual contact patterns.

This study examined the factors affecting individuals' decisions whether to consult with a GP or the municipality's emergency ward (EW), which is intended for urgent treatment. 
Previous studies conducted in Oslo (Goth \& Berg, 2011, Goth, Berg \& Akman, 2010 ) pointed out the importance of both time of residence and country of birth and their impact on the utilization of primary health care services. Based on the results we specify the following two main hypotheses:

Heterogeneity hypothesis:

Immigrants differ in their propensity to visit the EW compared to the rest of the population.

Duration of residence hypothesis:

The probability of EW visits among immigrants is influenced by their duration of residence in the country.

We expected that one of the main factors that contribute to variation in the use of emergency services is the individual's probability of experiencing an emergency. In addition, we expected that age and gender influences the probability of seeking primary medical care.

\section{Data and methods}

\subsection{Data set and study population}

The data set is based on two independent public registries merged by Statistics Norway (SSB). Demographic data with socio-demographic details for residents of Oslo born after 1987 were collected from the official National Population Register and merged with data routinely collected from consultation records. The latter forms the basis for GPs' reimbursements. Only residents consulting either the EW and/or GP in 2006 and 2007 are included. Since we do not have information on non-users, they are not a part of the study population.

In Oslo, the primary-care sector has a homogeneous structure and organization; hence, concern about heterogeneity in the organizational structure of the primary sector is thus accounted for by restricting our sample to inhabitants of Oslo.

The data file included repeated observations of each individual. We accounted for individual-specific, unobservable heterogeneity related to the choice between consulting a GP or an EW. Renewal of prescriptions, telephone and email consultations are not included in the data set. We accounted for unobservable heterogeneity at the level of the individual by estimating two random effects in logistic regressions that address our two hypotheses. We distinguished between immigrants belonging to the 14-largest migrant populations, other migrants, and residents born in Norway (Statistisk sentralbyrå, 2006). 


\subsection{Variables}

The outcome variable is the observed utilization of the EW. We included "indicators of immigration background" and "indicators of birth country" as explanatory variables. Individuals' ages, genders, and lengths of residence were included, in addition to the total number of yearly contacts with primary-care services. Unfortunately the data does not include information on health status or socio economic variables.

The operational categorization of variables "Immigrant," "Birth Country," and "Duration of Residence" were based on Statistics Norway's definitions (Statistics Norway, 2009).

All primary-care consultations, both GP consultations and EW consultations, in Oslo for the years 2006 and 2007 are registered. A total of 1,935,000 consultations are included, and all are individuals born before1987 ( $\geq 19)$. We distinguished between the 14largest immigrant groups as of 2006, according to Statistics Norway. In descending order according to population, the groups are from the following countries: Sweden, Denmark, Iraq, Pakistan, Somalia, Bosnia and Herzegovina, Iran, Germany, Vietnam, Poland, United Kingdom, Russia, Turkey, and Sri Lanka (Statistics Norway, 2010). Data analysis was performed by means of maximum likelihood using STATA 11.

\section{Results}

The results are organized as follows:

- Descriptive statistics are presented in Table 1.

- In section 3.1, we present the estimation results when estimating the impact of different immigration backgrounds on the probability of seeking emergency care.

- Results from estimating the impact of time since migration for the subsample of immigrants with two non-Norwegian-born parents are presented in section 3.2.

Residents from Norway's two neighbouring countries, Sweden and Denmark, have a different utilization pattern; the proportion of emergency ward visits is almost 50 percent higher among people from Sweden than the corresponding proportion among people from Denmark. We observed, however, that on average, individuals from Denmark have been in Norway for a longer period compared to individuals from Sweden.

Similarly, we observed that individuals from Great Britain who have spent an average of more than 18 years in Norway also have a relatively low proportion of emergency ward visits, while individuals from Iraq and Russia, who have an average duration of residence of less than 8 years, have a relatively high proportion of emergency ward visits.

\subsection{Are immigrants more likely to use emergency services?}

\section{Descriptive statistics}

Table 1 contains a description of the relative sizes of groups with different immigration backgrounds. This table shows that the two dominant groups consist of individuals without an immigrant background (73 percent) and individuals who were both born outside of Norway and have two non-Norwegian parents. 
Table 1: Use of emergency services according to background for residents of Oslo based on data collection in a 2-year period 2006-2007.

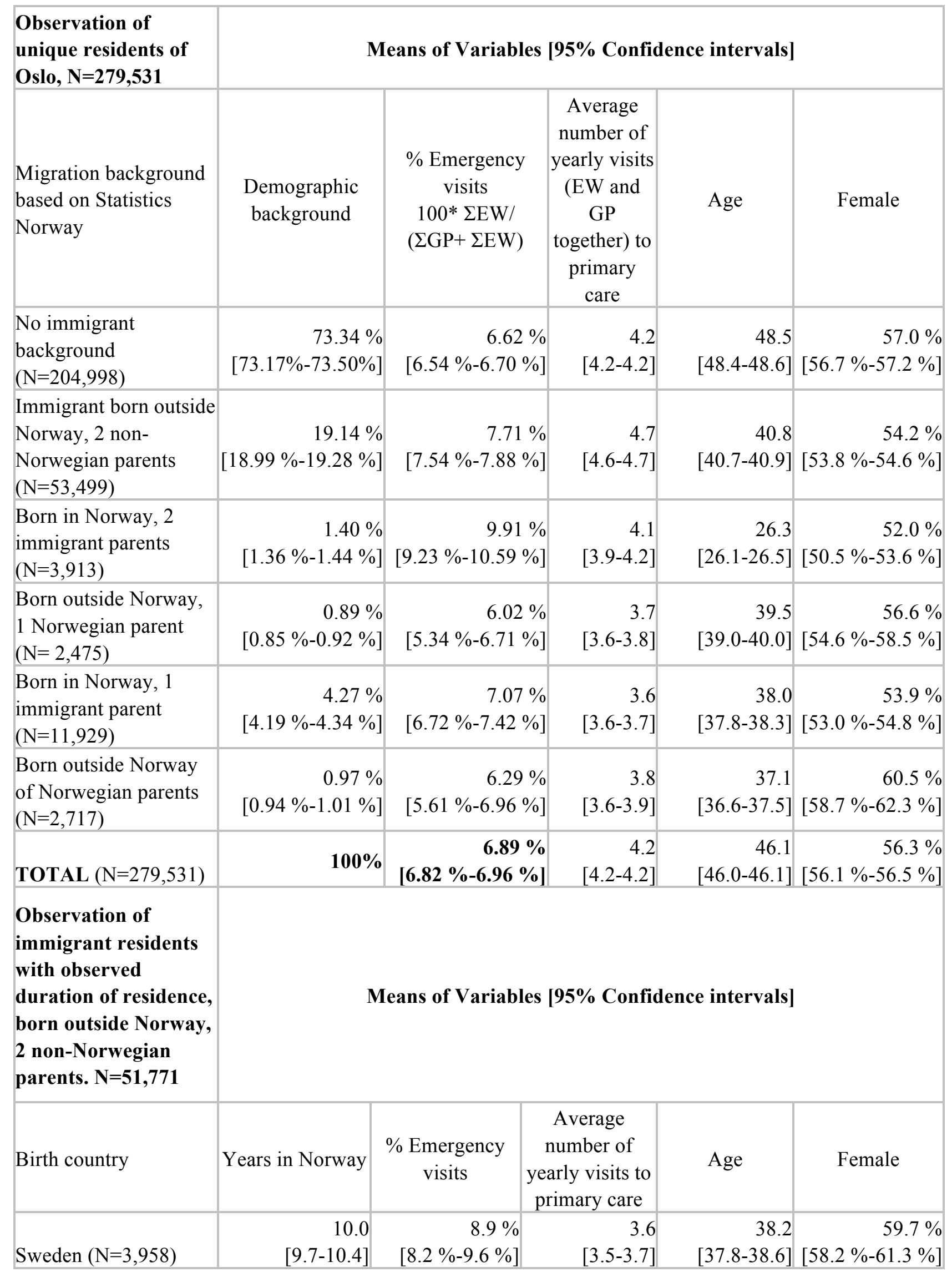




\begin{tabular}{|c|c|c|c|c|c|}
\hline Denmark $(\mathrm{N}=1,675)$ & $\begin{array}{r}21.6 \\
{[20.8-22.4]}\end{array}$ & $\begin{array}{r}6.0 \% \\
{[5.1 \%-6.9 \%]}\end{array}$ & $\begin{array}{r}4.0 \\
{[3.8-4.2]}\end{array}$ & $\begin{array}{r}50.6 \\
{[49.8-51.4]}\end{array}$ & $\begin{array}{r}55.8 \% \\
{[53.4 \%-58.1 \%]}\end{array}$ \\
\hline Poland $(\mathrm{N}=1,458)$ & $\begin{array}{r}11.0 \\
{[10.5-11.6]}\end{array}$ & $\begin{array}{r}10.0 \% \\
{[8.7 \%-11.3 \%]}\end{array}$ & $\begin{array}{r}3.9 \\
{[3.7-4.0]}\end{array}$ & $\begin{array}{r}41.0 \\
{[40.3-41.6]}\end{array}$ & $\begin{array}{r}57.6 \% \\
{[55.1 \%-60.2 \%]}\end{array}$ \\
\hline $\operatorname{Iraq}(\mathrm{N}=1,920)$ & $\begin{array}{r}7.6 \\
{[7.4-7.8]}\end{array}$ & $\begin{array}{r}8.9 \% \\
{[8.0 \%-9.7 \%]}\end{array}$ & $\begin{array}{r}5.5 \\
{[5.2-5.7]}\end{array}$ & $\begin{array}{r}34.2 \\
{[33.7-34.6]}\end{array}$ & $\begin{array}{r}44.6 \% \\
{[42.4 \%-46.9 \%]}\end{array}$ \\
\hline Germany $(\mathrm{N}=1,013)$ & $\begin{array}{r}15.7 \\
{[14.6-16.7]}\end{array}$ & $\begin{array}{r}5.3 \% \\
{[4.2 \%-6.3 \%]}\end{array}$ & $\begin{array}{r}3.8 \\
{[3.6-4.0]}\end{array}$ & $\begin{array}{r}45.9 \\
{[44.8-46.9]}\end{array}$ & $\begin{array}{r}59.2 \% \\
{[56.2 \%-62.3 \%]}\end{array}$ \\
\hline Bosnia $(\mathrm{N}=1,205)$ & $\begin{array}{r}12.5 \\
{[12.2-12.8]}\end{array}$ & $\begin{array}{r}7.8 \% \\
{[6.8 \%-8.9 \%]}\end{array}$ & $\begin{array}{r}4.7 \\
{[4.4-4.9]}\end{array}$ & $\begin{array}{r}42.6 \\
{[41.7-43.5]}\end{array}$ & $\begin{array}{r}53.7 \% \\
{[50.9 \%-56.5 \%]}\end{array}$ \\
\hline Somalia $(\mathrm{N}=2.660)$ & $\begin{array}{r}8.9 \\
{[8.7-9.1]}\end{array}$ & $\begin{array}{r}11.7 \% \\
10.8 \%-12.5 \%]\end{array}$ & $\begin{array}{r}5.0 \\
{[4.9-5.2]}\end{array}$ & $\begin{array}{r}34.8 \\
{[34.4-35.2]}\end{array}$ & $\begin{array}{r}52.8 \% \\
{[50.9 \%-54.7 \%]}\end{array}$ \\
\hline Pakistan $(\mathrm{N}=6,113)$ & $\begin{array}{r}16.6 \\
{[16.4-16.9]}\end{array}$ & $\begin{array}{r}7.0 \% \\
{[6.6 \%-7.4 \%]}\end{array}$ & $\begin{array}{r}5.7 \\
{[5.6-5.9]}\end{array}$ & $\begin{array}{r}39.6 \\
{[39.2-39.9]}\end{array}$ & $\begin{array}{r}51.3 \% \\
{[50.1 \%-52.6 \%]}\end{array}$ \\
\hline Vietnam $(\mathrm{N}=1.903)$ & $\begin{array}{r}16.6 \\
{[16.2-16.9]}\end{array}$ & $\begin{array}{r}5.3 \% \\
{[4.5 \%-6.1 \%]}\end{array}$ & $\begin{array}{r}4.3 \\
{[4.1-4.5]}\end{array}$ & $\begin{array}{r}40.1 \\
{[39.5-40.7]}\end{array}$ & $\begin{array}{r}58.6 \% \\
{[56.4 \%-60.9 \%]}\end{array}$ \\
\hline Russia (N=746) & $\begin{array}{r}7.3 \\
{[6.8-7.7]}\end{array}$ & $\begin{array}{r}6.0 \% \\
{[4.8 \%-7.2 \%]}\end{array}$ & $\begin{array}{r}4.2 \\
{[4.0-4.5]}\end{array}$ & $\begin{array}{r}37.2 \\
{[36.3-38.1]}\end{array}$ & $\begin{array}{r}78.4 \% \\
{[75.5 \%-81.4 \%]}\end{array}$ \\
\hline $\operatorname{Iran}(\mathrm{N}=2,323)$ & $\begin{array}{r}13.0 \\
{[12.7-13.2]}\end{array}$ & $\begin{array}{r}7.2 \% \\
{[6.5 \%-8.0 \%]}\end{array}$ & $\begin{array}{r}5.2 \\
{[5.0-5.4]}\end{array}$ & $\begin{array}{r}39.7 \\
{[39.2-40.2]}\end{array}$ & $\begin{array}{r}49.2 \% \\
{[47.1 \%-51.2 \%]}\end{array}$ \\
\hline Great Britain (N=937) & $\begin{array}{r}18.1 \\
{[17.0-19.1]}\end{array}$ & $\begin{array}{r}6.1 \% \\
{[4.9 \%-7.3 \%]}\end{array}$ & $\begin{array}{r}3.7 \\
{[3.4-3.9]}\end{array}$ & $\begin{array}{r}48.1 \\
{[47.1-49.1]}\end{array}$ & $\begin{array}{r}40.9 \% \\
{[37.7 \%-44.0 \%]}\end{array}$ \\
\hline Turkey $(\mathrm{N}=1,838)$ & $\begin{array}{r}14.8 \\
{[14.4-15.2]}\end{array}$ & $\begin{array}{r}8.0 \% \\
{[7.1 \%-8.9 \%]}\end{array}$ & $\begin{array}{r}5.4 \\
{[5.2-5.6]}\end{array}$ & $\begin{array}{r}37.7 \\
{[37.2-38.3]}\end{array}$ & $\begin{array}{r}48.7 \% \\
{[46.5 \%-51.0 \%]}\end{array}$ \\
\hline Sri Lanka $(\mathrm{N}=2,878)$ & $\begin{array}{r}13.2 \\
{[13.0-13.4]}\end{array}$ & $\begin{array}{r}8.0 \% \\
{[7.3 \%-8.7 \%]}\end{array}$ & $\begin{array}{r}5.2 \\
{[5.0-5.3]}\end{array}$ & $\begin{array}{r}39.1 \\
{[38.7-39.5]}\end{array}$ & $\begin{array}{r}51.6 \% \\
{[49.7 \%-53.4 \%]}\end{array}$ \\
\hline Other $(\mathrm{N}=21,144)$ & $\begin{array}{r}13.1 \\
{[12.9-13.2]}\end{array}$ & $\begin{array}{r}7.6 \% \\
{[7.3 \%-7.9 \%]}\end{array}$ & $\begin{array}{r}4.4 \\
{[4.4-4.5]}\end{array}$ & $\begin{array}{r}40.5 \\
{[40.3-40.7]}\end{array}$ & $\begin{array}{r}55.0 \% \\
{[54.3 \%-55.7 \%]}\end{array}$ \\
\hline TOTAL $(\mathrm{N}=51,771)$ & $\begin{array}{r}13.3 \\
{[13.2-13.4]}\end{array}$ & $\begin{array}{r}7.7 \% \\
{[7.6 \%-7.9 \%]}\end{array}$ & $\begin{array}{r}4.6 \\
{[4.6-4.7]}\end{array}$ & $\begin{array}{r}40.0 \\
{[39.9-40.2]}\end{array}$ & $\begin{array}{r}54.1 \% \\
{[53.7 \%-54.5 \%]}\end{array}$ \\
\hline
\end{tabular}

Table 1 indicates that the average proportion of emergency ward visits is lower in the group consisting of individuals born in Norway to two Norwegian-born parents compared to the other groups. There appears to be a difference in age between immigrant and nonimmigrant groups. Individuals with immigrant backgrounds appear to be younger than the average Norwegian-born individual. The lower proportion of emergency ward visits among individuals born in Norway with two Norwegian-born parents can partly be explained by differences in age. 
Table 2: The estimated impact of individual characteristics on the probability of seeking care at the $\mathbf{E W}$. Results from random effects logistic regression

\section{Independent variables}

Age. (Reference category

age $<25$ )

Age group 25-29

$0.6572 * * *$

$[0.6309,0.6847]$

Age group 30-34

$0.4981 * * *$

$[0.4777,0.5195]$

Age group 35-39

$0.4448^{* * *}$

$[0.4255,0.4649]$

Age group 40-44

$0.4034 * * *$

$[0.3849,0.4228]$

Age group 45-49

$0.3492 * * *$

$[0.3323,0.3669]$

Age group 50-54

$0.2895^{* * *}$

$[0.2750,0.3049]$

Age group 55-59

$0.2690^{* * *}$

$[0.2552,0.2836]$

Age group 60-64

$0.2529 * * *$

$[0.2397,0.2668]$

Age group 65-69

$0.2658 * * *$

[0.2501,0.2826]

Age group 70-74

$0.3016^{* * *}$

$[0.2834,0.3210]$

Age group 75-79

$0.4096^{* * *}$

[0.3866,0.4340]

$0.6402 * * *$

$[0.6055,0.6769]$

Age group 80-84

1.0128

$[0.9537,1.0756]$

Age group 90 or older

$2.1366^{* * *}$

$[1.9703,2.3170]$

Gender

$0.7155^{* * *}$

$[0.7008,0.7305]$

Yearly visits

$0.9734 * * *$

$[0.9717,0.9751]$

Immigrant background

(Reference category: No

immigrant background)

Immigrant born outside

$1.2009^{* * *}$

$[1.1705,1.2322]$

Norway, 2 non-Norwegian

parents.

Born in Norway, 2

$1.1177^{* * *}$

$[1.0314,1.2111]$

immigrant parents

Born outside Norway 1

0.9232

$[0.8227,1.0360]$

Norwegian parent

Born in Norway, 1

0.9949

$[0.9439,1.0487]$

immigrant parent

Born outside Norway of

0.9256

[0.8296,1.0327]

\section{Norwegian parents}

\begin{tabular}{lc}
\hline Number of Observations & 1934248 \\
\hline Number of individuals & 279531 \\
\hline $\begin{array}{l}\text { Average number of } \\
\text { observations. pr. individual: }\end{array}$ & 6.9 \\
\hline$* \mathrm{p}<.10, * * \mathrm{p}<.05, * * * \mathrm{p}<.01$ &
\end{tabular}


Table 2 contains the estimated impact of immigrant status and other observable variables on the probability of seeking care at the EW. Our results indicated that immigrants with non-Norwegian-born parents have a higher probability of seeking care at the EW compared to individuals without an immigration background $(\mathrm{p}<0.001)$. The results also suggested that females have a lower probability of emergency ward visits, and this effect appears to be stronger in magnitude, as measured by the odds ratio, than the impact of immigrant background. We also observed that the estimated odds ratio of the variable yearly visits is negative, i.e., frequent users of primary-care services are less likely to seek care at the EW in events of illness. We estimated the impact of age by grouping subjects into 16 different age categories, where the youngest group is the reference category. The results show that young individuals have a higher probability of seeking care at the EW compared with middle-aged individuals. We observed a pattern consistent with high probability of emergency ward visits among youths and the elderly, while individuals in their early 60s have the lowest probability of emergency ward visits. To give a visual impression of the impact of age, gender, and immigrant background, we computed the predicted probabilities based on the estimated parameters presented in Table 2 for an individual with two yearly visits, and these predicted probabilities are presented in figure 1. We observed that the probability of seeking care at the EW declines as individuals' ages rise, until a turning point is reached at age 65 , when the probability starts rising. 
Figure 1: The impact of age on predicted probabilities for seeking care at the EW Based on $1,934,248$ observations by 279,531 unique individuals with 6.9 average observations pr. individual.

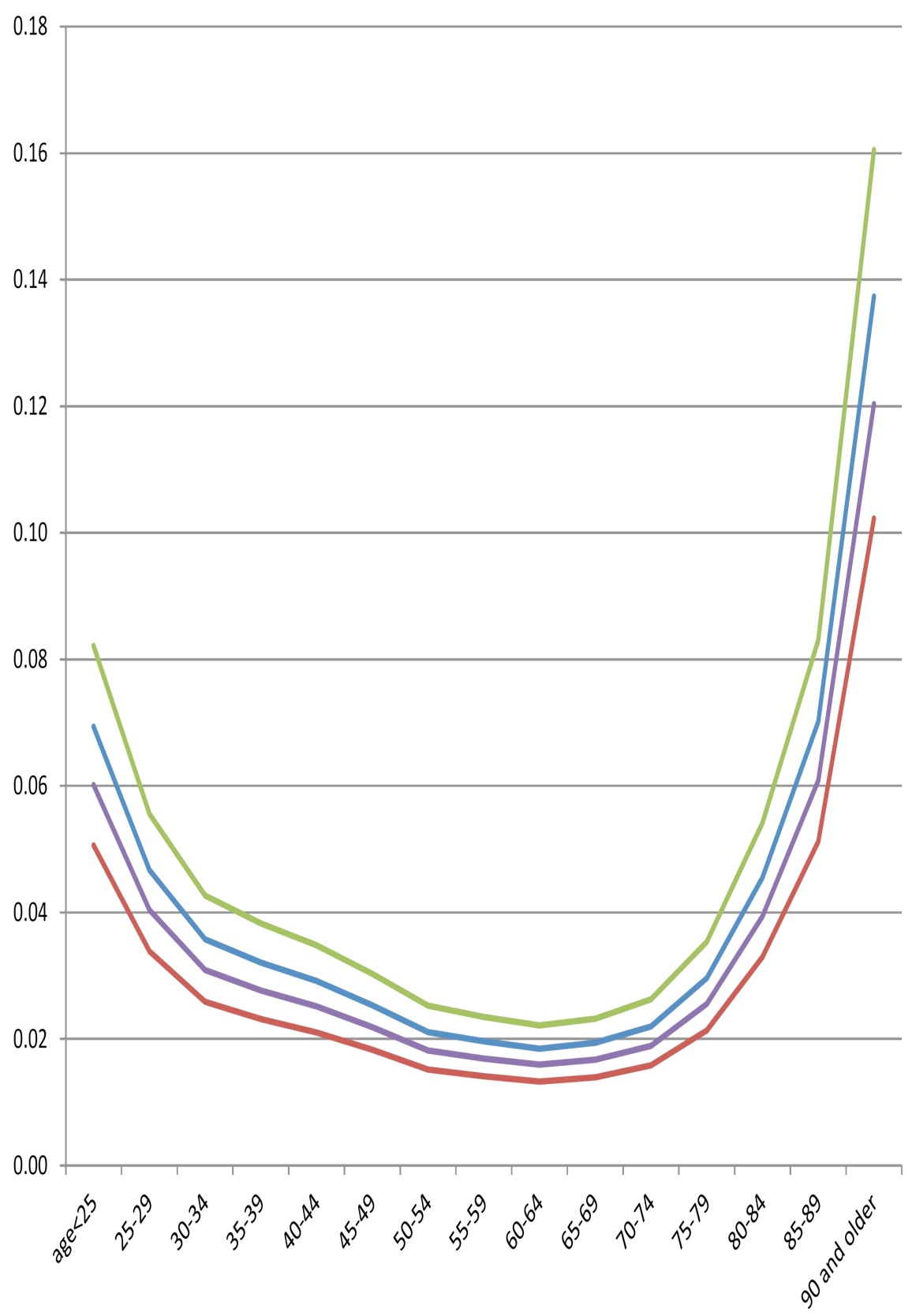

Number of obs.: 1934248.

Number of unique individuals: 279531. Average number of observations per individual: 6.9 .

- Male immigrant

-Male, non-immigrant

-Female immigrant

-Female, non-immigrant

\section{Age}

\subsection{Impact of duration of residence}

The results of estimating the impact of time since migration on the probability of visiting the EW are presented in Table 3. The model was estimated by means of a random effects logistic regression. Because the duration of residence is defined only for individuals with immigrant backgrounds, only individuals with immigrant backgrounds were included in this regression analysis. 
Table 3: The estimated impact of duration of residence among individuals with different birth countries, on the probability of seeking care at the EW. Results from random effects logistic regression.

\begin{tabular}{|c|c|c|}
\hline Independent variables & OR & [95 \% C.I.] \\
\hline \multicolumn{3}{|l|}{ Age. (Reference category age $<25$ ) } \\
\hline Age group 25-29 & $0.7418^{* * *}$ & {$[0.6866,0.8014]$} \\
\hline Age group 30-34 & $0.6053^{* * *}$ & {$[0.5593,0.6550]$} \\
\hline Age group 35-39 & $0.5422 * * *$ & {$[0.4998,0.5882]$} \\
\hline Age group 40-44 & $0.5176^{* * *}$ & {$[0.4750,0.5641]$} \\
\hline Age group 45-49 & $0.4526^{* * *}$ & {$[0.4122,0.4970]$} \\
\hline Age group 50-54 & $0.3892 * * *$ & {$[0.3502,0.4324]$} \\
\hline Age group 55-59 & $0.3242 * * *$ & {$[0.2878,0.3653]$} \\
\hline Age group 60-64 & $0.3400 * * *$ & {$[0.2965,0.3899]$} \\
\hline Age group 65-69 & $0.3685^{* * *}$ & {$[0.3125,0.4346]$} \\
\hline Age group 70-74 & $0.4625^{* * *}$ & {$[0.3811,0.5613]$} \\
\hline Age group 7579 & $0.5857 * * *$ & {$[0.4710,0.7283]$} \\
\hline Age group $80-84$ & $0.7129 * * *$ & {$[0.5524,0.9200]$} \\
\hline Age group 85-89 & 1.0849 & {$[0.7671,1.5342]$} \\
\hline Age group 90 or older & $2.9589 * * *$ & {$[1.6781,5.2172]$} \\
\hline Yearly visits & $0.9617 * * *$ & {$[0.9581,0.9652]$} \\
\hline Gender & $0.7446^{* * *}$ & {$[0.7098,0.7811]$} \\
\hline Female*Sweden*duration & 1.0000 & {$[1.0000,1.0000]$} \\
\hline Female*Denmark*stay & 1.0000 & {$[1.0000,1.0000]$} \\
\hline Female*Poland*stay & 1.0000 & {$[1.0000,1.0000]$} \\
\hline Female*Iraq*duration & $1.0001 * *$ & {$[1.0000,1.0002]$} \\
\hline Female*Germany*duration & 1.0000 & {$[1.0000,1.0000]$} \\
\hline Female*Bosnia*duration & 1.0000 & {$[1.0000,1.0001]$} \\
\hline Female*Somalia*duration & 1.0000 & {$[1.0000,1.0001]$} \\
\hline Female*Pakistan*duration & $1.0000 * * *$ & {$[1.0000,1.0000]$} \\
\hline Female*Vietnam*duration & 1.0000 & {$[1.0000,1.0000]$} \\
\hline Female*Russia*duration & 1.0000 & {$[1.0000,1.0000]$} \\
\hline Female*Iran*duration & 1.0000 & {$[1.0000,1.0001]$} \\
\hline Female* United Kingdom*duration & 1.0000 & {$[1.0000,1.0000]$} \\
\hline Female*Turkey*duration & 1.0000 & {$[1.0000,1.0000]$} \\
\hline Female*Sri Lanka*duration & 1.0000 & {$[1.0000,1.0000]$} \\
\hline Female*other migrant*duration & 1.0000 & {$[1.0000,1.0000]$} \\
\hline Sweden & 1.1023 & {$[0.9731,1.2486]$} \\
\hline Denmark & $0.6772 * * *$ & {$[0.5405,0.8484]$} \\
\hline Poland & $1.2569 * *$ & {$[1.0390,1.5204]$} \\
\hline Iraq & 1.1047 & {$[0.9150,1.3337]$} \\
\hline Germany & $0.6212 * * *$ & {$[0.4805,0.8031]$} \\
\hline Bosnia & 1.2603 & {$[0.8280,1.9184]$} \\
\hline Somalia & $1.2867 * * *$ & {$[1.0878,1.5220]$} \\
\hline Pakistan & $0.8898 *$ & {$[0.7881,1.0047]$} \\
\hline Vietnam & 0.7928 & {$[0.5749,1.0933]$} \\
\hline Russia & $0.6956^{* *}$ & {$[0.5183,0.9337]$} \\
\hline Iran & 0.9416 & {$[0.7562,1.1726]$} \\
\hline United Kingdom & 0.8233 & {$[0.6156,1.1010]$} \\
\hline Turkey & 1.0441 & {$[0.8452,1.2897]$} \\
\hline
\end{tabular}




\begin{tabular}{|c|c|c|}
\hline Sri Lanka & 1.0486 & {$[0.8554,1.2854]$} \\
\hline Sweden*duration & $0.9622 * * *$ & {$[0.9514,0.9732]$} \\
\hline Denmark*duration & 0.9904 & {$[0.9781,1.0029]$} \\
\hline Poland*duration & $0.9677 * * *$ & {$[0.9542,0.9813]$} \\
\hline Iraq*duration & $0.9682 * * *$ & {$[0.9460,0.9908]$} \\
\hline Germany*duration & $0.9839 * *$ & {$[0.9685,0.9994]$} \\
\hline Bosnia*duration & $0.9607 * *$ & {$[0.9274,0.9952]$} \\
\hline Somalia*duration & 1.0052 & {$[0.9873,1.0234]$} \\
\hline Pakistan*duration & $0.9887 * * *$ & {$[0.9804,0.9972]$} \\
\hline Vietnam*duration & $0.9683 * * *$ & {$[0.9482,0.9887]$} \\
\hline Russia*duration & 0.9935 & {$[0.9623,1.0258]$} \\
\hline Iran*duration & $0.9836^{*}$ & {$[0.9669,1.0006]$} \\
\hline United Kingdom*duration & $0.9701 * * *$ & {$[0.9541,0.9863]$} \\
\hline Turkey*duration & $0.9817 * *$ & {$[0.9680,0.9956]$} \\
\hline Sri Lanka*duration & $0.9834 * *$ & {$[0.9686,0.9984]$} \\
\hline Other migrant*duration & $0.9797 * * *$ & {$[0.9733,0.9861]$} \\
\hline Duration $^{\wedge} 2$ & $1.0003 * * *$ & {$[1.0001,1.0004]$} \\
\hline Number of observations & 387927 & \\
\hline Number of unique individuals.: $n=$ & 51771 & \\
\hline $\begin{array}{l}\text { Average nr. of observations per } \\
\text { individual }\end{array}$ & 7.5 & \\
\hline
\end{tabular}

The estimated impact of the duration of residence and birth country among immigrants on the probability of seeking care at the emergency ward is based on 387,927 observations of 51,771 individuals, with an average of 7.5 observations per individual, and was estimated by means of random effects logistic regression. We allowed for the impact of the duration of residence to show variation between males and females and to be dependent on birth country. In this way, we may investigate whether time since migration influenced individuals originating from different countries differently. In addition, by including the square of the duration of residence, Duration ${ }^{\wedge}$, we may also test whether a marginal increase in time since migration influences the probability of emergency ward visits differently when the time since migration is short compared with a longer time since migration. In the results presented here we have included a common Duration ${ }^{\wedge}$ - term for all the countries. We also fitted an unrestricted model with country-specific Duration ${ }^{\wedge}$ terms. By means of a likelihood-ratio test we tested the restricted model against the unrestricted. The simple model with a common Duration ${ }^{\wedge} 2$ term was not rejected. We observed that the duration of residence has a negative and statistically significant effect among the immigrants from all countries except for Denmark, Somalia, Russia, and Iran. Hence, we find support for our second hypothesis, that the duration of residence influences the probability of seeking care at the EW. We also observed that the estimated odds ratio of Duration ${ }^{\wedge} 2$ is significantly larger than one, which indicates that the marginal impact of the duration of residence on the probability of emergency ward visits is smaller when many years have passed since migration. Table 3 shows that the estimated impact of the variable Female*Iraq*residence has an estimated odds ratio larger than one. This suggests that the impact of the time since migration is smaller for females from Iraq than for males from the same country. A similar effect can be observed for females from Pakistan. Figure 2 gives a visual impression of how duration of residence influences the 
probability of seeking care at the EW (based on estimated parameters presented in Table 3 ) as it varies by birth country.

Figure 2: The estimated impact of years of residence on the probability of an emergency visit for a female aged 45 with two primary care consultation per year, across different birth countries

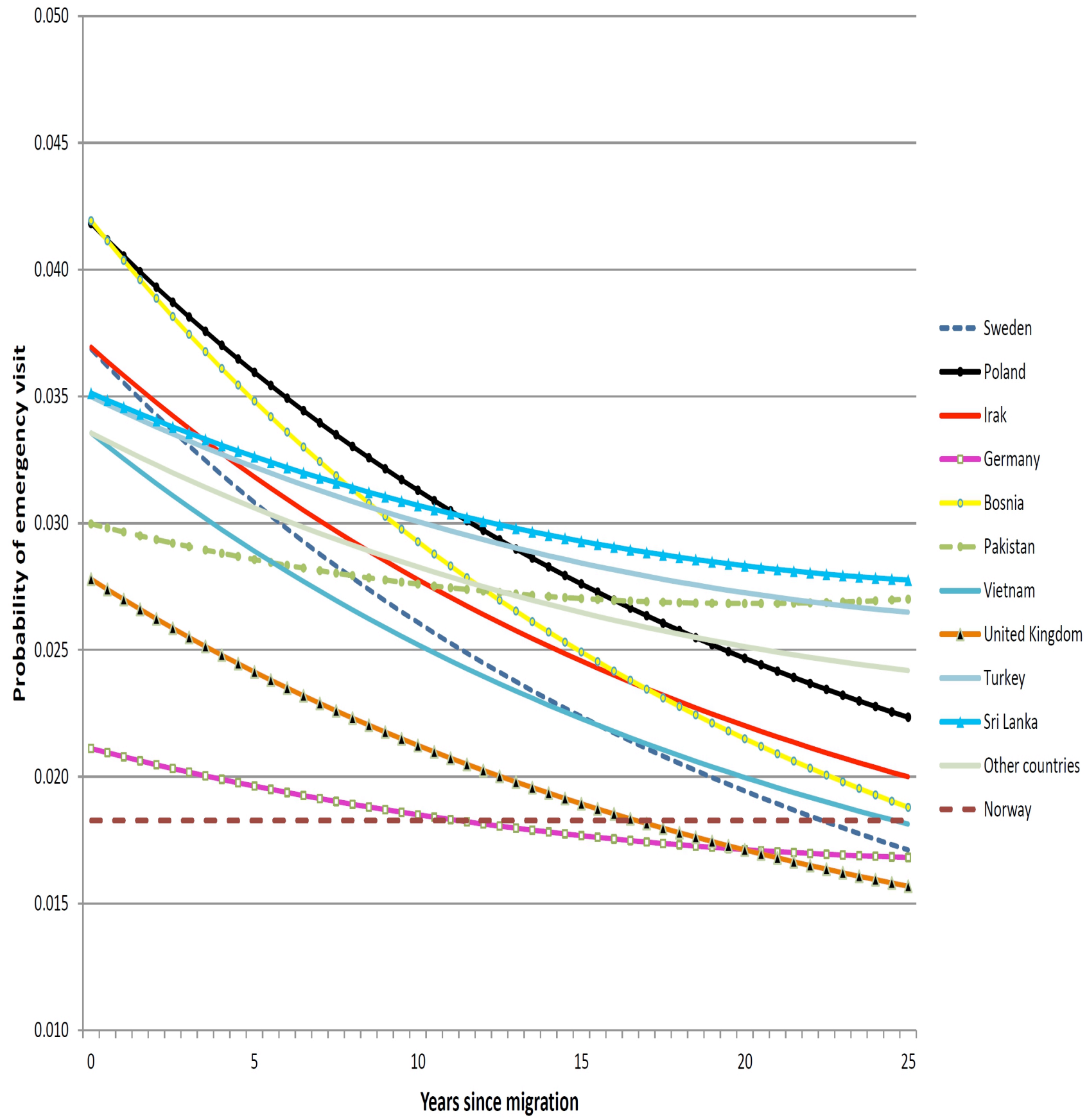

In figure 2, we have fixed the age and gender variables as well as the number of yearly visits, and the presented probabilities are for a female at 45 years with two primary-care consultations per year. In order to compare these conjectures with the predicted probability of a similar Norwegian woman, we have, for reference, included in figure 2 the corresponding predicted probability for a Norwegian woman with the same observable 
characteristics. This predicted probability is not related to the measure of the duration of residence and is therefore a flat line. Predicted probabilities for immigrants from Denmark, Russia, Somalia, and Iran are not included because the duration of residence did not have a statistically significant effect for people from these countries.

\section{Discussion and conclusion}

Based on over 1.9 million consultations, our results presented in Table 2 support the hypothesis that immigrants differ from the group of Norwegian-born with two Norwegian parents with respect to EW utilization. Further, our results presented in Table 3 suggest that dimensions such as birth country and duration of residence account for much of this variation. We find support for the second hypothesis, that duration of residence influences the utilization of emergency ward services. We thus find that immigrants are not a homogeneous group with respect to choice of provider, a result confirmed by other European studies (Hargreaves et al., 2006, Norredam et al., 2004, Norredam et al, 2007). In fact, the results suggest that the differences in the probability of seeking care at the EW between a newly arrived immigrant and an immigrant from the same country who has been living in Norway for many years can be larger in magnitude than differences between individuals from different birth countries. The decreasing probability corresponds to results from previous studies (Krasnik \& Paulsen, 2009, Blom, 2008). Hence, one could argue that the duration of residence and age are key factors explaining the use of services at the EW.

Immigrants to Norway, who have surmounted the obstacles of European migration laws, might be healthier than those who do not leave their countries of origin. This "healthy migrant effect" is likely to wear off with time (Williams, 1993). Although this effect would not necessarily influence utilization of GPs versus EW services, better health - other factors being equal - would be expected to dampen one of the tendencies found in this study: migrants with shorter tenure in Norway use emergency ward services more frequently. As studies of EW use show, there is a higher utilization rate among immigrants compared to the rest of the population (Blom, 2008, Dyhr, Andersen \& Enghom, 2007). Our results show that age- and gender-related variations in health utilization showed the same trends as previous studies (Dyhr, Andersen \& Enghom, 2007, Steihaug \& Rutle, 1997).

Mainstream models like the GP Scheme are designed for the majority population. This implicates an expectation that minority groups with their heterogeneity are expected to use the same health-care services with the same frequency as the majority population. Results from qualitative studies (Goth \& Berg, 2011) indicate that possible explanations for the differences include linguistic and cultural barriers experienced by the new arrivals. These barriers are likely to mitigate as time goes by, and the reduction in EW utilization may thus partly be caused by better access to information. A postulation confirmed by both Norwegian and Danish studies (Goth \& Berg, 2011, Goth, Berg \& Akman, 2010, Norredam et al., 2004, Norredam et al, 2007) reveals that informal barriers such as a lack of familiarity with the system, lack of information, and lack of accessibility to their GP are reasons why some individuals prefer EWs to GP appointments. Preventing sickness, one of the main purposes of GPs, might be seen as a foreign concept.

There are some limitations that need to be acknowledged. Data for the present study include only residents contacting a GP during the given time period. This suggests that we cannot account for residents without contact. Furthermore, country definitions by Statistics Norway do not capture the diversity of ethnic populations within countries of origin (e.g.,regarding the Kurdish population in Turkey, Iran, and Iraq). 
Growing cultural diversity presents a challenge to equitable health care (Chaturvedi \& McKeigue, 1994). Developing capacities to respond to the diverse range of new migration challenges will require avoiding a "one size fits all" policy in primary health-care services. The results of Norwegian studies (Goth \& Berg, 2011, Goth, Berg \& Akman, 2010, Goth, 2010) indicate a lack of information received by migrants regarding the primary health system and suggest that this is a significant obstacle. The following question may be raised: "Is the diversity of migrant backgrounds and circumstances affecting migrants' ability to navigate the health-care system?" Measuring how migrants are succeeding in the Norwegian health-care system will require disaggregated data and a diversity in categorization of migrants (Norredam, Nielsen \& Krasnik, 2009) for years to come. This study suggests areas in which data collection could focus and help distinguish subpopulations of particular interest.

Research is needed to illuminate both the reception and comprehension of initial information provided by the authorities and comprehension about the GP Scheme, initially to all residents.

\section{Acknowledgement}

This work was financially supported by the Norwegian Extra Foundation for Health and Rehabilitation through EXTRA funds (grant number: YC82XY/Nasjonalforening for Folkehelse). The National Centre for Emergency Primary Health Care (Unifob Bergen) developed the idea and original protocol drafts for this part of the project, and the authors thank the Centre for Emergency Primary Care for its contribution. The authors also thank Professor John E. Berg, PhD, at the Oslo and Akershus University College for Applied Sciences for his advice and ideas in the development of present protocol. The authors are grateful for comments and suggestions from the participants from the Royal Norwegian Ministry of Health and Care Service and the Norwegian Directorate of Health, in March 2012 and participants at the research forum at the Southern and Eastern Norway Regional Health Authority, Health Services Research Centre in March 2011.

\section{Ethics approval}

Regional Committees for Medical and Health Research Ethics (REK) approved this research project and the construction of the database.

Rules of law for medical and health research are given in the Research Ethics Act and the Health Research Act. Furthermore, the owner of the registries, the Directorate of Health, NAV, and the Ministry of Health and Care services gave their approval to use their data for the purposes of the study.

* Correspondence to: Ursula S. Goth, Oslo and Akershus University College for Applied Sciences, Postboks 4, St. Olavs Plass, 0130 Oslo. Telephone: +47 95965969 Email: Ursula.smaaland.goth@hioa.no 


\section{References}

Blom, S. (2008). Innvandrernes helse 2005/2006 [Immigrant Health 2005/2006]. Oslo: Statistisk sentralbyrå [Statistics Norway]. Accessed 20 June 2011 from: http:/www.ssb.no/emner/00/02/rapp_200835/rapp_200835.pdf

Chaturvedi, N., \& McKeigue, P. M. (1994). Methods for epidemiological surveys of ethnic minority groups. Journal of Epidemiology and Community Health, 48(2), 107-111.

Dyhr L, Andersen J.S, Enghom G. (2007) The pattern of contact with general pratice and casualty departments of immigrants and non- immigrants in Copenhagen, Denmark. Danish Medical Bulletin, 54(3):226-9.

Goth, U. G. S. (2010). Informasjon om fastlegeordningen til flerkulturelle befolkningsgrupper: En utfordring for helsevesenet. Utposten, 39(5), 20-23.

Goth, U. G. S., \& Berg, J. E. (2011). Migrant participation in Norwegian health care: A qualitative study using key informants. European Journal of General Practice, 17(1), 28-33. doi: $10.3109 / 13814788.2010 .525632$

Goth, U. G. S., Berg, J. E., \& Akman, H. (2010). The intercultural challenges of general practitioners in Norway with migrant patients. International Journal of Migration, Health and Social Care, 6(1), 26-33. doi: 10.5042/ijmhsc.2010.0447

Hargreaves, S., Friedland, J. S., Gothard, P., Saxena, S., Millington, H., Eliahoo, J., et al. (2006). Impact on and use of health services by international migrants: Questionnaire survey of inner city London A\&E attenders. BMC Health Services Research, 6, 153. doi: 10.1186/1472-69636-153

Helse- og omsorgsdepartementet [Norwegian Ministry of Health and Care Services] (2003).

Resept for et sunnere Norge: Folkehelsepolitikken (St. med nr 16 (2002-2003)) [Public Health Policy]. Oslo: Helse- og omsorgsdepartementet

Helsedirektoratet [Norwegian Directorate for Health and Social Affairs]. (05.01.2011). I gjennomsnitt 1200 innbyggere per fastlege [On average, 1200 inhabitants per doctor ]. Oslo: The Directorate. Retrieved 28.07.2011 from:

http://www.helsedirektoratet.no/refusjonsordninger/tall_analyse/fastlege/i_gjennomsnitt_1200 innbyggere per fastlege 782604

Huijts, T., \& Eikemo, T. A. (2009). Causality, social selectivity or artefacts? Why socioeconomic inequalities in health are not smallest in the Nordic countries. European Journal of Public Health, 19(5), 452-453. doi: 10.1093/eurpub/ckp103

Krasnik, A., \& Paulsen, B. (2009). Reforming primary health care. In J. Magnussen, K. Vrangbæk \& R. B. Saltman (Eds.), Nordic health care systems: Recent reforms and current policy challenges (pp. 233-254). Maidenhead: McGraw-Hill. Retrieved 28.02.2011 from: HYPERLINK http://www.euro.who.int/_data/assets/pdf file/0011/98417/E93429.pdf

Norredam, M., Krasnik, A., Sorensen, T.H., Keiding N., et.al (2004). Emergency room utilization in Copenhagen: a comparison of immigrant groups and Danish-born residents. Scand J Public Health, 32(1), 53-59. doi: 10.1080/14034940310001659.

Norredam, M., Mygind, A., Nielsen, A. S., Bagger, J., \& Krasnik, A. (2007). Motivation and relevance of emergency room visits among immigrants and patients of Danish origin. European Journal of Public Health, 17(5), 497-502. doi: 10.1093/eurpub/ck1268 
Norredam, M., Nielsen, S., Krasnik, A., (2009). Migrants'utilization of somatic healthcare services in Europe - a systematic review. European Jouranl of Public Health, 20 (5)

Statistics Norway. (2009). Variable definitions. Oslo: SSB. Retrieved 28.02.2011 from:

http://www.ssb.no/english/metadata/definitions/variables/main.html

Statistics Norway. (2011). Immigration and immigrants. Oslo: SSB. Retrieved 28.07.2011 from: http://www.ssb.no/english/subjects/00/00/10/innvandring en/

Statistisk sentralbyrå [Statistics Norway]. (2006). De 15 største gruppene $i$ innvandrerbefolkningen 1. januar 2001 og 1. januar 2006 [The 15 largest immigrant groups January 1st , 2001 and January 1st, 2006 ]. Oslo: SSB. Retrieved 28.02.2011 from: http://www.ssb.no/innvbef/arkiv/ttab-2006-05-11-01.html

Steihaug S. Rutle O. (1997) Legesøkning blant pakistanske innvandrere. (Consultation among immigrants from Pakistan) Tidsskr Nor Lcereforen, 117:2440-3.

Westin, S., \& Krokstad, S. (2003). Fokehelse og sosial ulikhet [public health and social inequality ]. In Ø. Larsen, A. Alvik, K. Hagestad \& M. Nylenna (Eds.), Helse for de mange: samfunnsmedisin i Norge (pp. 221-231). Oslo: Gyldendal akademisk.

Williams, R. (1993). Health and length of residence among south Asians in Glasgow: A study controlling for age. Journal of Public Health Medicine, 15(1), 52-60. 